\title{
Music Therapy and Aromatherapy Interventions in Patients undergoing Hemodialysis: A Systematic Review
}

\section{Sariati Sariati, Dwi Uswatun Sholikhah, Cahya Mustika Narendri, Gevi Melliya Sari and Qolbi Nur Qoidah Yahya}

Faculty of Nursing, Universitas Airlangga, Surabaya, Indonesia

\begin{abstract}
Introduction: The number of patients with chronic kidney disease (CKD) who undergo hemodialysis is increasing every year. Various attempts have been made to maximize the process of hemodialysis, one of which is by providing complementary therapy with music as therapy and through the administration of aromatherapy. The aim of this study was to identify the effectiveness of the use of music therapy and aromatherapy in a patient diagnosed with chronic kidney disease undergoing hemodialysis.
\end{abstract}

Methods: The literature review followed on from the identification of the interventions then the studies were identified by keyword according to the topic and title. There were 15 articles that discussed the effect of music therapy and aromatherapy on patients undergoing hemodialysis. The design RCT was 7 articles, 3 quasi-experimental articles, and 5 clinical trial articles.

Results: Music can raise the endorphin and serotonin levels and reduce the catecholamine levels, so it can change the respiratory rate and oxygen saturation, improve their quality of sleep and reduce fatigue.

Conclusion: Our findings indicate that music therapy and aromatherapy have a positive effect on patients with chronic kidney disease undergoing hemodialysis.

\section{ARTICLE HISTORY}

Received: Dec 26, 2019

Accepted: Dec 31, 2019

\section{KEYWORDS}

music therapy; aromatherapy; haemodialysis

\section{CONTACT}

Dwi Uswatun Sholikhah

$\triangle$ dwi.uswatun.sholikhah2018@fkp.unair.ac.id

$\equiv$ Faculty of Nursing, Universitas Airlangga, Surabaya, Indonesia

Cite this as: Sariati, S., Sholikhah, D. U., Narendri, C. M., Sari, G. M., \& Yahya, Q. N. Q. (2019). Music Therapy and Aromatherapy Interventions in Patients undergoing Hemodialysis: A Systematic Review.Jurnal Ners, 14(3si), 81-85. doi:http://dx.doi.org/10.20473/in.v14i3(si).16990

\section{INTRODUCTION}

Chronic kidney disease (CKD) is characterized by a decrease in the amount of permanent glomerular filtration rate (Muhammad Luqman Prihananda, Arina Maliya, 2014). CKD is one of the diseases that can impose a heavy economic burden on communities (Hassan Babamohamadi, Nemat Sotodehasl , Harold G. Koenig, Changiz Jahani, 2015). The number of patients undergoing hemodialysis has increased (Shabandokht-zarmi, Bagheri-nesami, \& Afshin, 2017). Hemodialysis is one of CKD treatment methods that has been recently used for people with kidney failure before they get a kidney transplant. The blood is removed from the waste products via an artificial kidney (Hassan Babamohamadi, Nemat Sotodehasl , Harold G. Koenig, Changiz Jahani, 2015). A patient diagnosed with CKD and undergoing the hemodialysis process can become stressed. This can involve and be due to the drug and diet therapy, hospitalization and compulsory addiction treatment, changes in their family ties, a reduction in their participation in social activities and employmentrelated economic losses (Muhammad Luqman Prihananda, Arina Maliya, 2014). CKD Patients undergoing hemodialysis may be exposed to many problems and acute complications such as anxiety, depression, hypertension, nausea, vomiting, headache, cramps, restlessness, confusion, syncope, arrhythmias, and convulsions (Kutlu \& Eren, 2014). The impact that can occur if the acute complications are not treated will decrease the quality of life of the patients (Shabandokht-zarmi et al., 2017).

Regarding the prevalence of kidney disease, 2 million patients in the world are undergoing hemodialysis (Hassan Babamohamadi, Nemat Sotodehasl , Harold G. Koenig, Changiz Jahani, 2015). 
The expected number of patients with ESRD in the United States will be almost 2,24 million by 2030 (Kutlu \& Eren, 2014). In Indonesia, the treatment of kidney disease is the second largest ranking of financing from health insurance after heart disease (Alcântara et al., 2018). In Indonesia, based on the Indonesian Hospital Association Data and Information Center, the number of patients with chronic kidney failure is estimated to be around 50 per one million residents, $60 \%$ of whom are adults (Lubis et al., 2009). The management of CKD patients in relation to the physical and psychological aspects using a complementary intervention of music therapy and aromatherapy intervention to CKD patients undergoing hemodialysis is intended to reduce any complications.

Music therapy and aromatherapy intervention are a complementary intervention in the medical field (Aisara, Azmi, \& Yanni, 2015) that is cost-effective, simple and with limited side effects (Hassan Babamohamadi, Nemat Sotodehasl , Harold G. Koenig, Changiz Jahani, 2015). The study consists of the recommended duration and types of music therapy and aromatherapy possible, and it also puts forward the benefits of the intervention. This summary is intended for health care providers worldwide who are involved in CKD care. The aim of this study was to identify the effectiveness of the use of a combination of music therapy and aromatherapy in patients diagnosed with chronic kidney disease undergoing hemodialysis.

\section{MATERIALS AND METHODS}

This paper reported on a complementary intervention in the nursing area since 2013-2018. The study adopted the systematic literature review methodology to clarify which method was more effective for CKD patients. By systematically reviewing the literature, we were able to synthesize the existing literature and empirical evidence in a transparent and replicable way in order to identify areas where the knowledge is still scarce and to point out future research questions to academics, practitioners and policymakers. From a range of 1189 papers in total, we identified 40 papers that need to be thoroughly revised and after we decided on the inclusion criteria, it limited the papers down to 15 focused on CKD patients.

The studies were identified by searching four electronic databases: Scopus, Science Direct, Pubmed and ProQuest. This was done using a combination of keywords and Boolean operators (AND and OR). The keywords were music therapy, aromatherapy, chronic kidney disease, complementary therapy, chronic disease and anxiety patient.

The inclusion criteria of the research were 1) experimental studies, 2) research conducted from 2013 to 2019 and 3) research samples or respondents who had been diagnosed with chronic kidney disease who were undergoing hemodialysis. There was no age limitation for the participants in the article,

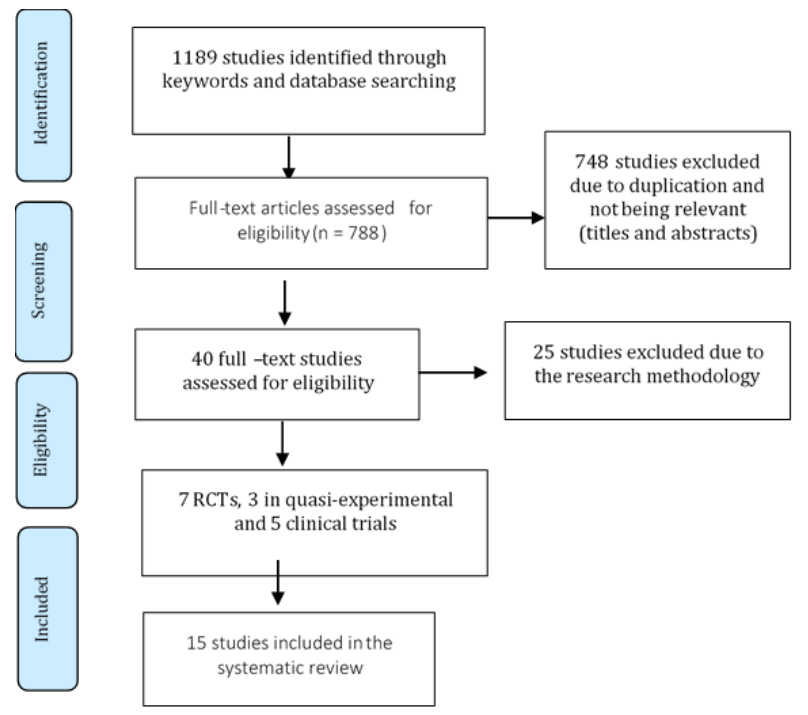

Figure 1. Flow diagram

because the focus of the search was on the chronic disease suffered by the participants. The articles were clarified if the results of the study did not explain the estimated effects of the intervention provided. During the selection process, studies focusing only on the effectiveness of the use of a combination of music therapy and aromatherapy in a patient diagnosed with chronic kidney disease undergoing hemodialysis were kept. The steps of the data selection and extraction have been reported in Figure 1.

\section{RESULTS}

The results of the review of 15 journal articles used in this study are related to the benefits of music therapy and aromatherapy for the patients undergoing hemodialysis. The total number of respondents in this review was 1065 participants who had been diagnosed chronic kidney disease and who were undergoing hemodialysis. The researcher found there to be some benefits of music therapy and aromatherapy for people undergoing hemodialysis. A combination of music therapy and aromatherapy decreased the heart rate, blood pressure and breathing rate and provided relaxation and changes in the patient's pain perception. Lavender essential oil can also reduce the level of fatigue, and improve the quality of sleep and depression for patients undergoing hemodialysis. In total, 9 out of 15 articles discussed music therapy, and 6 out of 15 articles discussed aromatherapy for patients undergoing hemodialysis. Moreover, 12 out of the 15 articles revealed that music therapy and aromatherapy could reduce the patient's anxiety level; 3 articles stated that music therapy and aromatherapy can reduce pain in the patient. This was aligned with the introductory part of this study elaborating that music therapy and aromatherapy can reduce the anxiety of patients undergoing hemodialysis.

The genre of music was not set by the researcher. Slow music in rhythm that is more instrumental is recommended (Lin, Lu, Chen, \& Chang, 2012). Music 
with a slow tempo and calm characteristics can lead to a harmony of the soul (Lin et al., 2012). Aromatherapy has variances like lavender (Hassanzadeh, Kiani, Bouya, \& Zarei, 2018), (Bagherinesami, Espahbodi, \& Nikkhah, 2014), (Arzu Senturk, MD, 2018) and sweet orange (Muz \& Tasci, 2017) rose (Dehkordi, Tayebi, Ebadi, Sahraei, \& Einollahi, 2017), (Barati, Nasiri, Akbari, \& Sharifzadeh, 2016) in the context of hemodialysis. In Nasemi's writing, the effect of reducing pain in aromatherapy can be done for 10 minutes every time that a patient undergoes hemodialysis. The duration of the aromatherapy and music therapy given is different for each study, but it is between 15 - 30 minutes every session. The concentration given of the aromatherapy was $5 \%$ (Hassanzadeh et al., 2018). Inhalation aromatherapy seems to have fewer limitations and higher applications regarding the hemodialysis patients. Should it turn out to be effective, it can be utilized widely in treatment centers as a simple, low-cost method and it can be done alone by the patient (Muz \& Tasci, 2017).

For each study, the data from the full texts was extracted, including the publication year, title and keywords, including the authors, research questions, methodology, and main results. These were subject to thematic analysis about the CKD patients undergoing hemodialysis. See the Table 1 into supplementary file.

\section{DISCUSSION}

Music Therapy to Reduce Anxiety. Since the time of Al-Farabi and Ibn Sina, music therapy is one of the treatments that is used to help alleviate the complications associated with medical treatments (Muhammad Luqman Prihananda, Arina Maliya, 2014). Listening to music has positive effects of music on both pain and anxiety and on the quality of life of individuals (Muhammad Luqman Prihananda, Arina Maliya, 2014), (Lin et al., 2012). Listening to music is an effective tool for distraction. It can influence the levels of morphine 6 glucuronide and interleukins- 6 , raise the endorphin and serotonin levels, reduce the catecholamine levels, increase the activity of the alpha brainwaves and create a cheerful atmosphere of endorphins. This can lead to engendering hemodynamic changes including decreasing the heart rate, blood pressure (Kutlu \& Eren, 2014) and breathing rate, and providing relaxation (Lin et al., 2012). Music can improve one's mood psychosomatically as well as through psycho-neuroendocrine-immunology (PNEI). It does this by encouraging physical relaxation (Lin et al., 2012). The genre of the music was not set by the researcher. Slow music in rhythm that is instrumental is recommended (Lin et al., 2012). Music with a slow tempo that has calm characteristics can lead to the harmony of the soul and taste (Lin et al., 2012). The duration of listening to music was for about 30 minutes every session (Kutlu \& Eren, 2014).

Music Therapy to reduce Pain Level. Music therapy can decrease pain as stated by the gate control theory which suggests that music activates the type II sensory fibers (group Ab), which trigger the inhibitory interneurons that block the transmission of pain signals to the brain. Thus the gate is considered closed and the patients can enjoy a reduction or neutralization of their pain perception (Lin et al., 2012) (Francesco Burrai, Valentina Micheluzzi, Maria Pia Zito, Giurdanella Pietro, 2014). Music requires powerful mental processes involved in the concentration that modifies the transmission of pain impulses in the spinal cord by also providing stimuli that competes with other peripheral nerve impulses which arrive from the SNP to the CNS by transferring the brain's focus from the nociceptors to the sound signal (Lin et al., 2012).

The types of aromatherapy used in this study were lavender, rose and orange aromatherapy. The duration of the aromatherapy and music therapy given was different for each study, and it was between 15 - 30 minutes for every session.

Aromatherapy has variances; lavender (Hassanzadeh et al., 2018), (Bagheri-nesami et al., 2014), (Arzu Senturk, MD, 2018), sweet orange (Muz \& Tasci, 2017), and rose (Dehkordi et al., 2017), (Barati et al., 2016) can be used to help hemodialysis patients. In Nasemi's writing, the effect of reducing pain in aromatherapy can be done for 10 minutes every time a patient undergoes hemodialysis. The concentration given to aromatherapy is $5 \%$ (Hassanzadeh et al., 2018). Inhalation aromatherapy seems to have fewer limitations and higher applications for hemodialysis patients. Should it turn out to be effective, it can be utilized widely in treatment centers as a simple, low-cost method and it can be done alone by the patient (Barati et al., 2016).

Aromatherapy reduces fatigue. Aromatherapy is considered to treat physical and mental disorders through the use of herbal essences. Aromatherapy can have a sedative analgesic and antispasmodic effect through the neurological system. Lavender has 2 ingredients; linalool and linalyl acetate. Linalool has an effect on the GABA (Gama- Aminobutyric acid) receptors in the central nervous system, where it acts as a sedative. Linalyl acetate also has narcotic properties (Hassanzadeh et al., 2018). Lavender essential oil can reduce the level of fatigue. Aromatherapy has a variety. In this study, lavender and sweet orange can be used to reduce the fatigue in patients undergoing hemodialysis (Muz \& Tasci, 2017). In practice, lavender and sweet orange oils (1:1) were dropped onto a gauze bandage, which was placed $5 \mathrm{~cm}$ away under the nose. The patients had to smell the aromatic mixture at this distance for 2 minutes. They were asked to take deep breaths three times after smelling the mixture was completed. This procedure can be followed before sleeping every day (Muz \& Tasci, 2017). The study by Hassanzadeh on aromatherapy with a combination Benson relaxation technique was effective at reducing fatigue. Aromatherapy can be given when a patient is undergoing hemodialysis over 15-20 minutes by inhalation. 
Aromatherapy reduces pain. In the study by Nesami, they explained that lavender aromatherapy can reduce the pain of the patients undergoing hemodialysis with an arteriovenous fistula. Lavender aromatherapy has a psychological effect (Barati et al., 2016). Inhaled lavender essence was given at a concentration of $10 \%$ for 5 min during 3 hemodialysis sessions (Barati et al., 2016).

Aromatherapy reduces anxiety, depression, and stress. Aromatherapy has a variance, which is damask rose. Damask rose can be used to strengthen the nerves and to reduce anxiety and depression. The psychological effect caused by aromatherapy is that it can reduce anxiety, depression and stress (Dehkordi et al., 2017). Aromatherapy given before going to bed for 30 minutes can reduce anxiety (Arzu Senturk, MD, 2018) and it can be given through inhaled with a constant density of $2 \%$ from a piece of cloth smeared with three drops for an hour.

Aromatherapy for sleep quality. The effect of aromatherapy can improve sleep quality when giving the aromatherapy is done every day before the patient goes to bed. It can be done 30 minutes before going to bed (Muz \& Tasci, 2017) (Arzu Senturk, MD, 2018). The patients were trained to drip 2 drops of lavender oil onto the cotton in the box and to place it at a distance of $15-20 \mathrm{~cm}$ away from the pillow. The patients were instructed that they were to drip lavender oil onto a new piece of cotton every night (Arzu Senturk, MD, 2018).

\section{CONCLUSION}

Music therapy and aromatherapy are recommended to reduce pain and anxiety levels, increase oxygen saturation, increase the quality of sleep and to improve the mood of patients undergoing hemodialysis. There is no negative effect of giving the music therapy and aromatherapy intervention. Nursing care for hemodialysis patients is very important. Patients need support to follow this program. To improve the physical and psychological factors of the patient, the nurse can give them therapy that is complementary such as aromatherapy during hemodialysis. Aromatherapy and music therapy have a positive effect on patients undergoing hemodialysis.

\section{REFERENCES}

Aisara, S., Azmi, S., \& Yanni, M. (2015). Gambaran Klinis Penderita Penyakit Ginjal Kronik yang Menjalani Hemodialisis di RSUP Dr. M. Djamil Padang. FK Unand, 7(1), 42-50. Retrieved from http://jurnal.fk.unand.ac.id

Alcântara, G., Melo, A., Rodrigues, A. B., Firmeza, M. A., Sandro, A., \& Grangeiro, D. M. (2018). Musical intervention on anxiety and vital parameters of chronic renal patients : a randomized clinical trial. https://doi.org/10.1590/1518-8345.2123.2978

Arzu Senturk, MD, P. T. K. (2018). The Effect of Lavender Oil Application via Inhalation Pathway on Hemodialysis Patients' Anxiety Level and Sleep Quality,

324-335.
https://doi.org/10.1097/HNP.00000000000002 92

Bagheri-nesami, M., Espahbodi, F., \& Nikkhah, A. (2014). Complementary Therapies in Clinical Practice The effects of lavender aromatherapy on pain following needle insertion into a fi stula in hemodialysis patients, 20, 1-4. https://doi.org/10.1016/j.ctcp.2013.11.005

Barati, F., Nasiri, A., Akbari, N., \& Sharifzadeh, G. (2016). The Effect of Aromatherapy on Anxiety in Patients, $8(5)$. https://doi.org/10.5812/numonthly.38347.Rese arch

Cantekin, I., \& Tan, M. (2013). The Influence of Music Therapy on Perceived Stressors and Anxiety Levels of Hemodialysis Patients, 35(September 2012), 105-109. https://doi.org/10.3109/0886022X.2012.73629 4

Dehkordi, A. K., Tayebi, A., Ebadi, A., Sahraei, H., \& Einollahi, B. (2017). Effects of Aromatherapy Using the Damask Rose Essential Oil on Depression, Anxiety, and Stress in Hemodialysis Patients: A Clinical Trial, 9(6), 6-10. https://doi.org/10.5812/numonthly.60280.Rese arch

Francesco Burrai, Valentina Micheluzzi, Maria Pia Zito, Giurdanella Pietro, D. S. (2014). Effects Of Live Saxophone Music On Physiological Parameters, Pain, Mood And Itching Levels In Patients Undergoing Haemodialysis, 249-257.

Hassan Babamohamadi, Nemat Sotodehasl , Harold G. Koenig, Changiz Jahani, R. G. (2015). The Effect of Holy Qur'an Recitation on Anxiety in Hemodialysis Patients: A Randomized Clinical Trial, 1921-1930. https://doi.org/10.1007/s10943-014-9997-x

Hassanzadeh, M., Kiani, F., Bouya, S., \& Zarei, M. (2018). Complementary Therapies in Clinical Practice Comparing the effects of relaxation technique and inhalation aromatherapy on fatigue in patients undergoing hemodialysis. Complementary Therapies in Clinical Practice, 31, 210-214.

https://doi.org/10.1016/j.ctcp.2018.02.019

Kutlu, A. K., \& Eren, G. (2014). Effects of music on complications during hemodialysis for chronic renal failure patients, 777-784. https://doi.org/10.1111/hdi.12161

Lin, Y., Lu, K., Chen, C., \& Chang, C. (2012). The Effects of Music as Therapy on the Overall Well-Being of Elderly Patients on Maintenance Hemodialysis, (250). https://doi.org/10.1177/1099800411413259

Lubis, A. R., Tarigan, R. R., Nasution, B. R., Ramadani, S., Vegas, A., Hipertensi, D. N.-, ... Sumatera, U. (2009). Pedoman penatalaksanaan gagal ginjal kronik, 1-31.

Maria, C., \& Neme, B. (2018). The effect of music therapy on hemodialysis patients ' quality of life and depression symptoms, 1-9. https://doi.org/10.1590/2175-8239-JBN-20180023 
Muhammad Luqman Prihananda, Arina Maliya, K. (2014). Effect Of Classical Music Therapy On The Anxiety Level Of Hemodialysis Patients At The Pku Muhammadiyah Hospital Of Surakarta.

Muz, G., \& Tasci, S. (2017). Effect of aromatherapy via inhalation on the sleep quality and fatigue level in people undergoing hemodialysis, 37, 28-35. https://doi.org/10.1016/j.apnr.2017.07.004
Shabandokht-zarmi, H., Bagheri-nesami, M., \& Afshin, S. (2017). Complementary Therapies in Clinical Practice The effect of self-selected soothing music on fi stula puncture-related pain in hemodialysis patients, 29 , 53-57. https://doi.org/10.1016/j.ctcp.2017.08.002 